\title{
The Lived Experience of Being a Foreigner
}

\author{
Zhou Wu \\ Graduate Student \\ Department of Elementary Education \\ University of Alberta
}

Currently I am doing my PhD in the area of teaching English as a second language. The thesis I am writing is entitled "Language, Consciousness and Personal Growth", in which a phenomenological approach is one of the instruments used for my autobiographic inquiry into how human consciousness grows and functions in language learning and acculturation. My interest in phenomenology is partly due to several courses I took at the University of Alberta, particularly Dr. van Manen's "Human Science Research in Pedagogy." This course does not only deal with the philosophical background of phenomenology in depth, but also gave the students the very practical knowledge of phenomenological writing as a research practice. This led to my article "The Lived Experience of Being a Foreigner." My interest in phenomenology is further developing.

Think thou how that this is not our home in this world, in which we are strangers, one not knowing another's speech and language. (The Diary of Samuel Ward, entry for May 13, 1595)

Several years ago, I was in West Germany with a group of Chinese technicians on a business tour. That was the first time I had ever been to a foreign country. What I first experienced of West Germany was the excitement of magnificent scenery, the amazing achievements of science and technology, and wonderful exotic food. We had nothing to worry about as our group was always together and everything was arranged by our friendly German hosts. I did not even feel uncomfortable in this new culture until one afternoon when I found I had some time to myself. I decided to go and buy a German-English dictionary in a nearby store. From the window of my hotel room, I could see this street very well. It was a downtown street with a lot of small shops on each side. I was sure that there would not be any difficulty for me to find a bookstore or a drugstore nearby. The street was not crowded, as seems to be always the case in that small town. People there were so polite and warm. They greeted everybody passing by with the south German expression Grüss Gott! Thus, I ventured to the street alone. Strangely, just a few steps away from the hotel, I suddenly felt my heart pumping excessively hard. What an unusual feeling. There seemed to be no reason for being nervous. I knew where to go and how to get back. We had shopped in Germany several times, so I knew what to say to buy things. Then why panic? I even felt that my steps were not even and steady as usual. Or maybe the 
ground I stepped on was not usual? It was a little like being in a dream, and the surroundings were dazzling for a moment.

However, nothing happened to me in that adventure. I bought what I wanted and returned to the hotel safely. I still remember that when I came back to my door, I had a feeling of relief. That German hotel to me was equally foreign as the German streets I had just been in, with its Gothic style of architecture, old- fashioned decorations and furniture, classical-western music at the entrance, not to mention the smell of butter and cheese that accompanied me every minute. But I did seem to feel home there at that moment.

Now I am living in Canada as a foreigner. Such strong sensations never occur when I walk in the streets in Edmonton. But the feeling of discomfort still arises in my life sometimes, which often makes me feel strongly that I am foreign. Of course, I also feel at home on many other occasions living in this country. What struck me is that this kind of feeling of at-homeness is especially significant to me as a foreigner. Is the nature of being foreign simply the other side of being at home? Is foreignness the lack of homeness, as darkness is often said to be the lack of light? Am I struggling in the twilight between the darkness of being "foreign" and the light of being "home"? To start this journey of phenomenological inquiry, I would like to see the inner conflict of a foreigner's self.

\section{The Awareness of Self}

Being a foreigner in Canada to me is not a bad experience at all. There are various kinds of excitement in leading a new life and experiencing a completely new world. It is especially valuable to share different cultural values and insights. What really makes me feel being foreign is the constant awareness of self.

An American coming to Japan made an interesting discovery about himself. He found he had a nose. He certainly had never thought of his American nose until he was surrounded by so many Japanese noses. To be a foreigner, one is always conscious of one's own self. This occurred to Wang right from the moment he stepped onto the Canadian Airliner flying to Vancouver. The first time wearing a tie made me feel uncomfortable. I needed to loosen it again and again. This made me look at the western man sitting beside me. I realized that my tie was not fixed in the same way as his. The knot I made was too small. And it was not as tight and neat as his. I tried to adjust it, but it always twisted to the right. I also found that my tie was hanging outside of my woollen shirt while the others all have theirs inside. With amusement I remembered how I had been impressed by my first "western" look when I put it on in front of the mirror in the Beijing Airport bathroom. The meal came. I had to hold my appetite to see how the others handled those forks and knives. They all put their napkins on their knees. Only babies need to do this in China. At night when I closed my eyes, I found that I was still watching myself from 


\section{University of Alberta}

the top of my head to the heels of my feet. I realized that one of my feet often tapped the floor rhythmically. In fact this was a habit of mine. It had never bothered me. But this time it put me on the alert. Do foreigners behave this way? Am I bothering the lady sitting in front? What is the acceptable way of sleeping in a foreign airliner? Is it OK if I stretch freely?

Like standing in front of a mirror, one notices a lot of things about oneself that one did not see before. A recognition of "me" occurs. This "me" is not the "self" one is familiar with. I am not only a stranger to others, but also becoming a stranger to myself.

Heidegger (Packer, 1985) distinguishes three modes of engagement that people have with their surroundings. He uses the example of a hammer. When using a hammer, we have no need for focal awareness of ourselves and our tool. The skills and practices we bring to our activity are so familiar to us that we are simply unaware of their existence. This is the ready-to-hand mode of activity. However, when some problem is encountered, such as the hammer proving too heavy for the job, its weightiness becomes salient; this breakdown of action represents the unready-to-hand mode. The present-at-hand mode is entered only when people detach themselves from an ongoing practical involvement in a project at hand. People have to "step back" and reflect. The hammer becomes an independent entity, removed from all tasks pursued.

Heidegger gives a positive account of the ready-to-hand mode. In this mode, people's actions and their situations fit each other. Because this is the mode of direct practical engagement in which we actually do much of our everyday living, this task amounts, for him, to the same thing as describing a human being. It gives us the most primordial and direct access to human phenomena.

However, it is just this primordial and direct access to human phenomena that is missing for foreigners. The tailored-fit relationship between people's actions and their situations no longer exists. They are constantly running into unready-to-hand situations and their action is always brought to the present-at-hand mode. The stepping back from "me" and recognition of "me" creates not only self reflection, but also self-conflict.

Linda talks about her self-consciousness in this paradoxical way:

On the one hand, I am always aware of what I am doing. My body which used to act automatically according to my will or without any consciousness is now like a puppet, always waiting for me to pull the controlling string. On the other hand, I am not sure of what I am doing. I need to get feedback. I need to know who I am by figuring out what image I have left in other's eyes. I cannot even make good judgments about myself. I need to get this sense from others.

This is just like Schutz's (1971) explanation: 
He who wants to use a map successfully has first of all to know his standpoint in two respects: its location on the ground and its representation on the map. A foreigner has to face the fact that he lacks any status as a member of the social group he is about to join and is therefore unable to get a starting-point to take his bearings. He is, therefore, no longer permitted in considering himself as the centre of his social environment, and this fact causes again a dislocation of his contour lines of relevance (p. 99).

\section{The Duality of Self}

Self-consciousness of being a foreigner always leads to the realization of the dissimilarities from others and their daily activities and social conventions. The ordinary social routines of one culture suddenly become awesome in the eyes of people from another culture. In fact, many people in their home culture would not mind finding themselves different from others. They may even try hard to make themselves stand out, since difference could mean being distinguished, original, or ingenious. People who deliberately distinguish themselves from others can be satisfied with what they did, as they know what they want and they do things according to what they want. Even if they were not satisfied with what they did, they then can easily revert to the shared social norm.

This does not happen to foreigners. Foreigners usually only have the idea of conformity to the dominant culture, but do not know exactly how they can achieve this, and they feel they are not doing what they want. The worst thing is that they do not have a way to retreat either. The differences between themselves and others cannot be a luxury they want to enjoy, but a flaw they want to cover or get rid of.

The mirror a foreigner is facing is a distorting mirror. The figure in front of him or her is not what one has expected to see. One becomes very cautious and carefully adjusts oneself to make a better image. It is not an easy job at all. Being a foreigner, I cannot satisfy myself with what I do. How could my eyes become so keen that I always see my own flaws? Not my eyes only, but also my ears. Before I came to Canada, I thought my English was quite good. I enjoyed my pronunciation and intonation, which won me the prize for the English Speaking Contest in my university. But now, when I hear my voice, I just hate it. If my ears have good reason to hate my mouth, my mouth also has good argument against my ears. How many times it missed the points of the jokes, and made the mouth too embarrassed to respond? How often the mouth had to ask to clarify the meaning not comprehended by the ears? My eyes cannot relax and trustfully look into the world either. How badly they see this new world. On the one hand they make a fuss of the trivial ordinary things which everybody takes for granted. On the other hand they overlook lots of important events and meaningful actions.

The process of inner conflict may lead to great distress. It is not simply that my ears hate my mouth, or my mouth hates my eyes. The inner 


\section{University of Alberta}

conflict inhabits my entire being. It makes me feel that my own "self" is falling apart. Now I have two "me"s inside myself. A "me" with whom I am familiar and with whom I feel connected. This is the "me" I enjoyed and was proud of. And I am still proud of it and would not let it go. The other "me" is a stranger. It is like a distorted figure that always appears whenever I am in the darkness of foreignness. I cannot accept it because I do not like to. I cannot reject it either because it is part of my own self. My old half hates my newly discovered half. It is also the newly acquired value that fights against the old value in my old half. To regain peace and confidence, a reorganization or reshaping of self is needed. This process is threatening, as one has to alter one's own identity, in order to accept this reincarnation.

\section{The Segmented Outer World}

The ancient oriental philosophers such as the Taoists stressed the wholeness of the world. The sky, the earth, the spirit, the kingdom, all these things from ancient times arise from One, and all these are touched by the virtue of wholeness (Lao Tsu, 1972, chap. 39). These ancient saints believed that wisdom emerges from the intuitive understanding of the world as a whole. Holistic thinking has also been advocated by Western thinkers such as Gestalt psychologists. They point out that the world cannot be possessed by cutting it into pieces. Without the grasp of the whole, the separate knowledge of parts is worthless. But foreigners living in a new country have no path to wholeness. For them, the holistic knowledge of that country and culture does not exist. Without such knowledge, it is impossible to make the connections among the separated events they have experienced. The world in their eyes remains fragmented.

Understanding a culture is like reading a text. People can experience a lot of enjoyment from reading. But the Book of Culture is by no means an easy one. After the excitement of the first few pages, or maybe even just a few lines, the readers get frustrated by incomprehension. Second-language learners are often annoyed by the interruption of new words, idiomatic expressions, unknown syntax structures in their reading. They cannot extract the meaning through the grasp of the context as most mature readers do. Often their attention is captured by the specific details such as isolated words or sentences. As they try hard to understand these details, they lose sight of the context of the whole. It is similar for foreigners who want to understand the unfamiliar phenomena in the new culture.

Once when I was teaching an undergraduate course in the University of Alberta, a student came in after the class had started. The room was quite full, and I noticed that she could not find a chair and seated herself on the floor. I saw an empty seat at the other end of the room and so I told her with a gesture. She seemed to have understood what I said. Yet a few minutes later, I found she was still sitting on the floor at the door. I was 
puzzled by her reaction to my suggestion and a string of questions came to me: Had she really understood what I said to her? Did I need to tell her again? From my cultural perspective, it was not comfortable to see a student suffering from sitting on the cold floor. But was it possible that she preferred sitting there and that was common in Canada? Might telling her the second time sound as if I was not happy with her sitting there and was imposing class discipline? I even thought that perhaps she did not like me and rejected me by ignoring my suggestions. I found at the moment I could not connect this incident to my other life experiences in order to make a sound judgement of the situation and a decision of my own reaction. The new world to me often disintegrates into such separate pieces, and I was not able to string them together.

I discussed earlier the idea that experientially there exist two "me"s within the inner world of a foreigner. And this duality also exists in the outer world. A foreigner's new world contrasts sharply with his or her old world. When I was first attending classes at the Canadian university, I was often amazed by the Canadian students' active contribution to the class. It seemed that everyone talked. They referred to various kinds of things in their life when they were discussing a single issue, whereas I mostly see the issue in an isolated way. I did read a lot. But I found that what I read only became meaningful when it connected to my past experience of my own country. In my mind, only that part of the world remained as a whole continent on which I could stand and move with freedom. My new world consisted of ice floes. I could recognize their existence as separated pieces, but they were too slippery for me to step on, nor was it possible for me to predict the directions of their movement.

\section{Me and the New World}

A foreigner who possesses a disorganized inner world and who inhabits an unconnected outer world finds everything paradoxical. On the one hand, the world the foreigner tries to understand collapses into pieces in front of him or her and becomes so elusive to grasp. On the other hand, this new world still remains real, rigid, gigantic, and overwhelming, in front of which the foreigner feels so tiny and weak.

The first foreign soil Wang stepped on was Vancouver, Canada. It was a rainy evening when he walked through the downtown streets. To him that night, Vancouver was a cold and hard world. The concrete of the street curbs, the steel rails of the stairways, and the walls of the buildings were all rigid and solid, demonstrating their objective existence, and confirming for him that he was on foreign soil. The cool wet air did not soften that world at all. Instead, he himself became stiffened. He had never seen such big buildings. The buses, lightposts, and even the pedestrians all appeared much larger. This experience evoked remote memories of his childhood. He felt like a little boy again as he remembered lying down on the floor, staring at the big pieces of furniture like huge buildings all around him. The noise of the streets, with the flashing 
lights on the cars, gave him the impression that he was confronting a powerful machine. He felt dwarfed and sensed that he was a small child in this big, unknown, and powerful world.

Not everybody has such specific experiences of a strange place as had Wang. However, many people do feel shocked when they face an overwhelming culture. We do hear people say: "In this culture, I feel I am like a newborn child." The encounter of a new cultural world is no less overwhelming than the encounter of a strange physical world. An American writer observes: "You can write a book about China after you are there for a week. However after a month of stay, you probably find that you can only write a few pages. And living there for a year, you may end up writing nothing."

When foreigners want to understand some problems of adult life in the host culture, they realize that they first have to know how the young are brought up in that culture. When they try to understand feminism as a women's issue, they hear more about how the society is dominated by men. When they want to join a group at a coffee-table conversation, they find that they have to go back home to watch a television program first. They may have read huge volumes of history, politics, and economics of the country, but still find that the basic knowledge, such as the routines of daily life, human relationship, and so forth, have not been touched yet. Indeed, they may even feel handicapped as if they were blind and deaf. They may feel ignorant as if they were illiterate. They may feel incompetent as if they were old. They may feel naive as if they were children. And yet, they are not blind and deaf because they do have light and sound within themselves. They are not illiterate, because they do have their own literacy. They are not old as they have burning energy inside. They are not children as they have mature hearts. And a mature heart is an unyielding heart. It will not accept its current status. It will constantly seek the light.

\section{Me and the Old World}

The light in the heart of a foreigner is his or her old world, the world where he or she was brought up. To many foreigners, grass on "that side" of the fence is always greener. In the remembrance of home, the cloudy skies, roaring storms, and piercing cold all fade away, and what is left is a wonderland full of beautiful sunshine. Many people do not realize how patriotic they are until they are away from their country.

Of course not everybody is patriotic. However the passion of their home land is irresistible. $\mathrm{Su}(\mathrm{Li}, 1989)$ had a narrow escape from China after the Tiananmen events in 1989. His memory of China was full of nightmares. He wrote about his homeland:

My country is what I have experienced. During the Cultural Revolution, my family and relatives had a very bad time. I was only fifteen, and I was demonstrated as the enemy to the public with my seventeen-year-old 
sister. All my family except my sister and me were in prison. After that I was sent to Hainan Island to do hard work for ten years. Though I had these bad experiences, I still wish I could go back. I worship the land. On that piece of land, I feel cultural belongingness. I believe I could do much more there. I cannot call it patriotism. But my affection is true. (p. 11)

The feeling of belonging occurs to me frequently since I have left my country. It could be caused by meeting someone from the home country. It may be triggered by a letter from home, a movie produced at home, a book about home, or even seeing or hearing the name of the home country. A piece of music can create strong feelings of emotion. One day my wife suddenly tuned in to a radio station that was broadcasting a piece of traditional Chinese music. I was busy working at the time. The music suddenly drew me to the radio. I put down my work. My wife was also standing there motionless. We looked at each other, and then both quietly sat down. We hushed our son, as if he could shatter the feeling. What a magic power that piece of music had! Our hearts trembled, echoing its beats, and the whole world at the moment was reverberating with its rhythm. I had listened to this song hundreds of times in China, but had never experienced a moment like this before.

In the music the walls that separated me from the outside world seemed to be crumbling, and gradually I emerged into the warmth of the surrounding. The music touched my roots. It brought me home. The music made me feel full and stable. Then I realized what belonging means. There is nothing political in its connotation, nothing racial, national, or geographic. This belonging is as down to earth and as pure as water. I feel a sense of belonging to that world for the simple reason that I am a part of it, and it is a part of me as well. In the new world, I am a drop of oil on the water. In contrast, in the old world, I am a part of this body of water. I feel my own power through the power of the whole.

The meaning of the old world to foreigners is often elusive. It is very hard to measure its volume. This body of water in the heart of a foreigner can be as vast as an ocean, as it often occupies his or her whole inner world. It may also crystallize to a valuable pearl, hanging like a drop on people's hearts and getting lost at times. To some people, the "old world" means their "home country." But sometimes it means "home town." And, quite often, a foreigner thinks about his or her own past home, or the people he or she loves. Perhaps mostly it is something beyond words. I am homesick, but I do not know what I am missing.

This feeling even remains in those who have settled in a foreign country for much longer than me. They say that the adding of years does not change much. The weight on the other side of the balance is always heavier. What changes is the meaning of home. As there are fewer people they miss and as the places they used to know and love disappear or change their appearance, they miss really nothing but their past. 


\section{University of Alberta}

\section{Past and Present}

Everybody treasures his or her old days. But for foreigners, this past has special meaning. Those who stay in their own country have a continuous and consistent history. Yet a foreigner shares no past with the native people. In Schutz's words, "Seen from the point of view of the approached group, he is a man without a history" (1971, p. 97). However from the point of view of the foreigner, his or her past has been severed and has become two unconnected pieces. Having undergone the disintegration and reorganization of his or her own self, and having established the new relationship with the world, the foreigner has gone through a profound change. This change is irreversible. To him or her, to recollect one's old memory is to dig out one's own identity, and to reevaluate oneself in a new light. That is to say, one has to find out the new connection between one's present existence and one's past and make it meaningful to one's own future. Not many foreigners can complete this reincarnation. Then the process of constantly seeking for at-homeness will last for ever, no matter that one is just longing for home, retreating to a protected corner as one's home, or striving to make the new world home.

\section{References}

Lao Tsu. (1972). Two Te Ching, A new translation by Gia-Fufeng and Jane English. New York: Vantage Books.

Li, Yi. (1989). From returning home to the establishment democratic front. Nineteen nineties, 58, 11-13. (A Chinese journal published in Hong Kong)

Packer, M.J. (1985). Hermeneutic inquiry in the study of human conduct American Psychologist, 40(10), 1081-1093.

Schutz, A. (1971). The stranger-An essay in social psychology. In Collected papers II (pp. 91-105). The Hague: Nijhoff. 